\title{
Genome-wide analysis of ATP-binding cassette $(A B C)$ transporters in the sweetpotato whitefly, Bemisia tabaci
}

\author{
Lixia Tian', Tianxue Song ${ }^{2}$, Rongjun He${ }^{1}$, Yang Zeng ${ }^{1}$, Wen Xie ${ }^{1}$, Qingjun Wuํ', Shaoli Wang ${ }^{1}$, Xuguo Zhou ${ }^{3 *}$ \\ and Youjun Zhang ${ }^{1 *}$
}

\begin{abstract}
Background: $A B C$ transporter superfamily is one of the largest and ubiquitous groups of proteins. Because of their role in detoxification, insect $A B C$ transporters have gained more attention in recent years. In this study, we annotated $A B C$ transporters from a newly sequenced sweetpotato whitefly genome. Bemisia tabaci $\mathrm{Q}$ biotype is an emerging global invasive species that has caused extensive damages to field crops as well as ornamental plants.

Results: A total of $55 A B C$ transporters containing all eight described subfamilies ( $A$ to $H$ ) were identified in the $B$. tabaci $Q$ genome, including 8 ABCAs, 3 ABCBs, 6 ABCCs, 2 ABCDs, 1 ABCE, 3 ABCFs, 23 ABCGs and 9 ABCHs. In comparison to other species, subfamilies $\mathrm{G}$ and $\mathrm{H}$ in both phloem- and blood-sucking arthropods are expanded. The temporal expression profiles of these $55 \mathrm{ABC}$ transporters throughout $B$. tabaci developmental stages and their responses to imidacloprid, a neonicotinoid insecticide, were investigated using RNA-seq analysis. Furthermore, the mRNA expression of $24 \mathrm{ABC}$ transporters (44\% of the total) representing all eight subfamilies was confirmed by the quantitative real-time PCR (RT-qPCR). Furthermore, mRNA expression levels estimated by RT-qPCR and RNA-seq analyses were significantly correlated $(r=0.684, p<0.01)$.

Conclusions: It is the first genome-wide analysis of the entire repertoire of $A B C$ transporters in $B$. tabaci. The identification of these $A B C$ transporters, their temporal expression profiles during $B$. tabaci development, and their response to a neonicotinoid insecticide lay the foundation for functional genomic understanding of their contribution to the invasiveness of $B$. tabaci.
\end{abstract}

Keywords: ATP-binding cassette transporter, Bemisia tabaci, Genome, Gene family expansion, Invasiveness

\section{Background}

ATP-binding cassette $(\mathrm{ABC})$ transporters constitute one of the largest protein superfamily and exists in all living organisms [1-3]. These transporters share highly conserved nucleotide binding domains (NBDs), which contain Walker $\mathrm{A}$, Walker $\mathrm{B}$ and a signature motif, the $\mathrm{C}$ loop, linking the two Walker boxes $[4,5]$. In addition to NBDs, a eukaryotic $\mathrm{ABC}$ transporter typically consists of one or two transmembrane domains (TMDs), which contain 6-11 membrane-spanning $\alpha$-helices and dictate substrate

\footnotetext{
*Correspondence: xuguozhou@uky.edu; zhangyoujun@caas.cn ${ }^{3}$ Department of Entomology, University of Kentucky, Lexington, KY 40546-0091, USA

'Department of Plant Protection, Institute of Vegetables and Flowers, Chinese Academy of Agricultural Sciences, Beijing 100081, China Full list of author information is available at the end of the article
}

specificity [1]. A classic domain architecture of a fulltransporter has a TMD-NBD-TMD-NBD arrangement from the $\mathrm{N}$ - to C-terminus, while half-transporters have only one set of NBD-TMD. Based on the homology of their NBDs, human $A B C$ transporters have been categorized into seven subfamilies, $\mathrm{ABCA}$ to $\mathrm{ABCG}$ [1]. $\mathrm{ABCH}$, which was first discovered in Drosophila melanogaster, exists in arthropods and zebrafish but not in mammals, plants and fungi [6-12].

Most ABC transporters encodes membrane-bound proteins that carry a wide range of molecules (e.g., amino acids, peptides, vitamins, sugars, lipids, sterols, hormones, endogenous metabolites, inorganics and xenobiotics) across membranes [1]. ABC transporters use energy released by ATP hydrolysis at the NBDs to 
transport molecular cargoes across the membrane. ABC transporters also function in cell signaling, ribosome assembly and translation $[3,13]$. For example, ABCE and $\mathrm{ABCF}$ proteins do not function as classic transporters but participate in transcription, translation and ribosome assembly $[14,15]$. Furthermore, plant ABC transporters also contribute to osmolality and phytoalexin functions (plant-pathogen interactions) [16].

The advent of Genomics Era has greatly improved our understanding of the diversity and function of invertebrate ABC transporters, including 56 in the fruit fly D. melanogaster [1], 64 in the water flea Daphnia pulex [13], 51 in the silkworm Bombyx mori [8], 73 in the red flour beetle Tribolium castaneum [17] and 103 in the spider mites Tetranychus urticae [10]. Based on the transcriptome data, Epis et al. suggested that $\mathrm{ABC}$ transporters were involved in the permethrin resistance in a malaria vector, Anopheles stephensi [18]. Similarly, ABC transporters were implicated in the degradation of plant secondary metabolites in the cotton bollworm, Helicoverpa armigera [19].

The sweetpotato whitefly, Bemisia tabaci (Gennadius) (Hemiptera: Aleyrodidae), is a phloem-feeding insect pest that cause substantial damages through feeding on over 600 host plants as well as by transmitting over 100 plant viruses [20]. As one of the most invasive pests, $B$. tabaci is generally considered as a species complex consisting of many biotypes or putative species with different biological and genetic characteristics [21]. The two most invasive and destructive B. tabaci biotypes are the Q (also known as Mediterranean, MED) and B (also known as Middle East-Asia Minor 1, MEAM1) [21]. B. tabaci has demonstrated a remarkable ability to develop resistance to insecticides in the field, including organophosphates, carbamates, pyrethroids, neonicotinoids and juvenile hormone mimics [22-24]. Insecticide was the driving force facilitating the $B$. tabaci biotype replacement events in China (B replaced indigenous biotypes in early 2000, and the subsequent replacement by $\mathrm{Q}$ in 2009) [25]. The overall goal of this research is to understand the involvement of ABC transporters, a family of phase III detoxification enzymes, in the metabolic resistance in $B$. tabaci. To archive this goal, we 1) provided the first genome-wide analysis of the entire repertoire of $\mathrm{ABC}$ transporters in the whitefly $B$. tabaci Q; 2) investigated the temporal expression profiles of these $\mathrm{ABC}$ transporters in different developmental stages; and 3) documented their transcriptomic response to imidacloprid, a neonicotinoid insecticide.

\section{Results and discussion}

Identification of $A B C$ transporters in $B$. tabaci

A total of $55 \mathrm{ABC}$ transporters was identified in $\mathrm{B}$. tabaci $\mathrm{Q}$ genome (Table 1). The number of $\mathrm{ABC}$ transporters in B. tabaci $\mathrm{Q}$ is comparable with other arthropod species; however, subfamilies $\mathrm{G}$ and $\mathrm{H}$ expanded in phloem- and blood-sucking arthropods (Table 2 and Additional file 1: Figure S1). For example, $\mathrm{ABCG}$ and $\mathrm{ABCH}$ account for $58 \%$ (42 and 16\%, respectively) of $\mathrm{ABC}$ transporters in the phloem-sucking B. tabaci, and 49\% (45 and 4\%, respectively) in the blood-sucking Cimex lectularius. The percentage reduces to $21 \%(18 \%+3 \%)$ in the red flour beetle, $T$. castaneum. The expansion of ABCG and ABCH subfamilies in these polyphagous and phloem-sucking arthropods, including the whitefly $B$. tabaci, the wheat aphid $D$. noxia and the spider mite T. urticae, suggest the potential contribution of $\mathrm{ABC}$ transporters to their adaptability and invasiveness. Phylogenetic analysis categorized the 55 B. tabaci ABC transporters into eight subfamilies (Fig. 1). To further understand the evolutionary placement of $B$. tabaci ABC transporters, in-depth phylogenetic analyses were conducted for each subfamily. The results of these analyses were described and discussed in the following sections.

\section{$A B C A$ subfamily}

A phylogeny tree of the eight ABCA proteins identified in $B$. tabaci and other organisms was presented in Additional file 2: Figure S2. All of the B. tabaci ABCA proteins are full-transporters (Table 1), which is consistent with $D$. pulex and $T$. urticae [10, 13]. The silkworm ABCA subfamily, in contrast, contains two full-transporters, one half-transporter and three incomplete $\mathrm{ABC}$ transporters [8]. Furthermore, no ABCA protein has been identified in yeast [26].

The B. tabaci ABCA subfamily has one of the largest B. tabaci ABC transporters, Btabq008198.1, encoding 1730 amino acids (Table 1). Btabq008198.1 clustered with the ABCA5 group, including Anopheles gambiae AGAp010416-PA, D. noxia DnXP_01537 5463.1 and $H$. sapiens ABCA5 cluster (hABCA5, 6, 8, 9 and 10) (Additional file 2: Figure S2). Although these ABCA5-related genes in mammalians (human, dog and mouse) cluster with ABCA5 on the same chromosomes [6,27], no counterpart of the ABCA5related genes has been identified in invertebrates, such as B. mori [8] and T. urticae [10]. Besides Btabq008198.1, the other seven B. tabaci ABCA genes (Btabq017043.1, Btabq003223.3, Btabq003232.1, Btabq 009375.1, Btabq009376.1, Btabq022409.1, and Btabq 022410.1) form a sister-group with a high bootstrap support. This sister-group clustered with $D$. noxia DnXP_015366480.1 (ABCA3), T. japonicas TjABCA3 and seven $T$. urticae genes. These genes then clustered with D. melanogaster DmCG31731 with a moderate bootstrap support. DmCG31731 was down-regulated in the salivary glands of a D. melanogaster E93 mutant [28]. As an early ecdysone responsive gene, E93 was a primary regulator of programmed cell death in D. melanogaster 


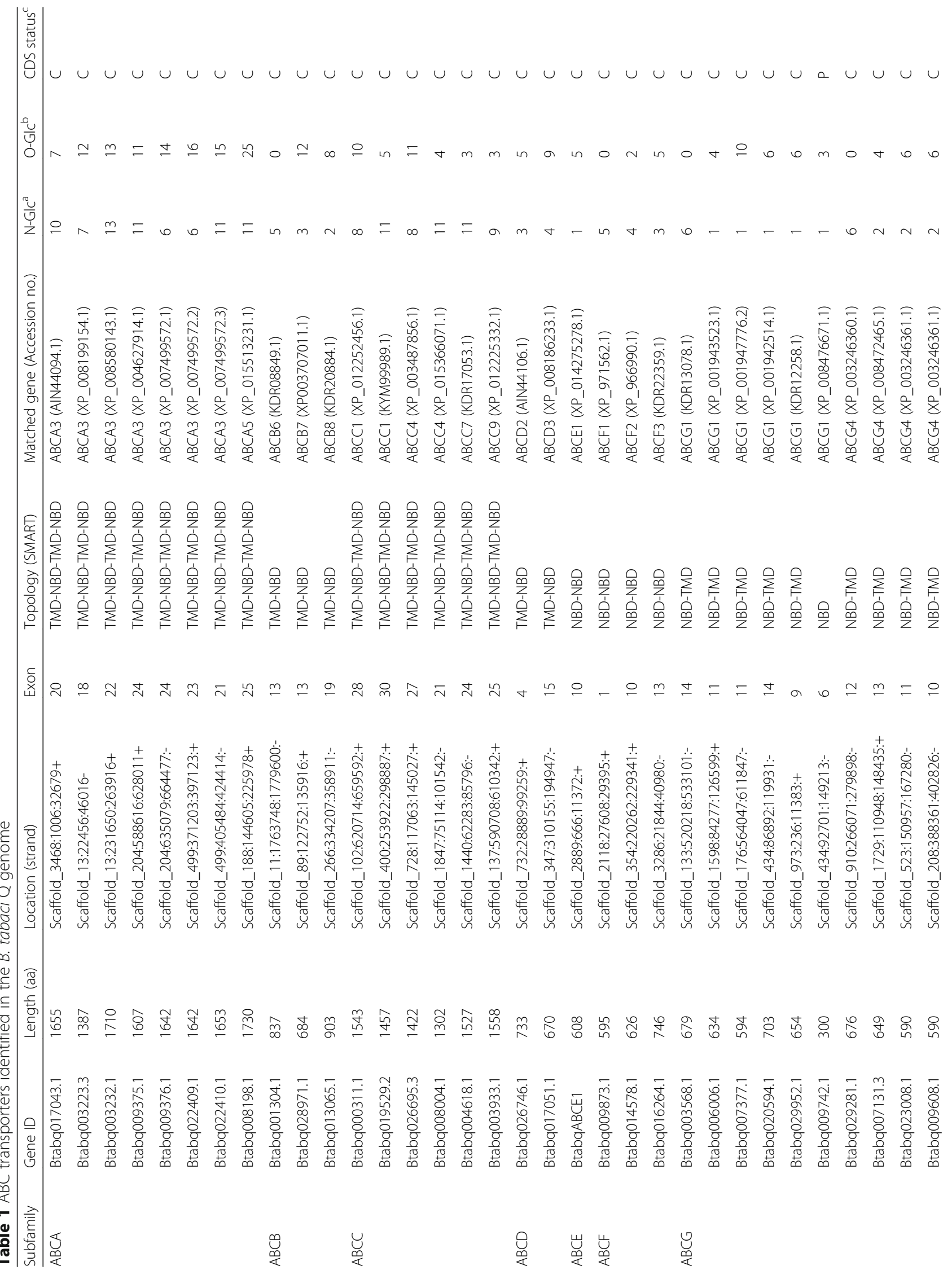




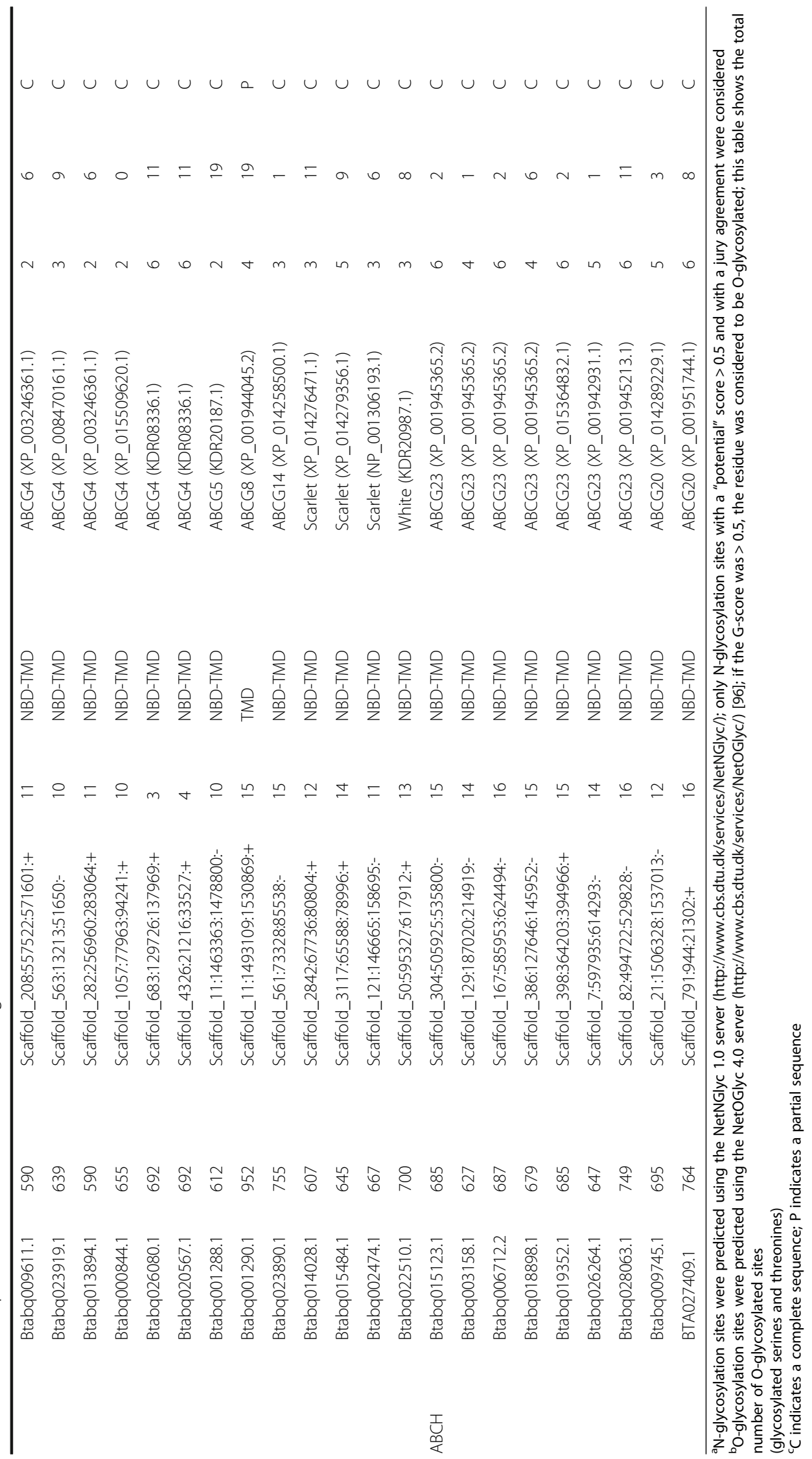


Table 2 The distribution of ABC transporter subfamilies in B. tabaci Q and in other arthropod species

\begin{tabular}{|c|c|c|c|c|c|c|c|c|c|c|c|}
\hline \multirow[b]{2}{*}{ Subfamily } & \multicolumn{3}{|c|}{ Phloem-sucking } & \multicolumn{3}{|l|}{ Blood-sucking } & \multicolumn{4}{|c|}{ Chewing/Sucking } & \multirow{2}{*}{$\begin{array}{l}\text { Chewing } \\
\text { T. castaneum }\end{array}$} \\
\hline & B. tabaci & D. noxia & T. urticae & An. gambiae & P. humanus & C. lectularius & A. mellifera & D. melanogaster & B. mori & H. armicoverpa & \\
\hline$\overline{A B C A}$ & 8 & 3 & 9 & 9 & 2 & 6 & 3 & 10 & 6 & 7 & 10 \\
\hline$A B C B$ & 3 & 6 & 4 & 5 & 6 & 7 & 7 & 8 & 8 & 11 & 6 \\
\hline$A B C C$ & 6 & 24 & 39 & 13 & 5 & 6 & 9 & 14 & 15 & 11 & 35 \\
\hline$A B C D$ & 2 & 3 & 2 & 2 & 2 & 2 & 2 & 2 & 2 & 2 & 2 \\
\hline$A B C E$ & 1 & 1 & 1 & 1 & 1 & 1 & 1 & 1 & 1 & 1 & 1 \\
\hline$A B C F$ & 3 & 3 & 3 & 3 & 3 & 4 & 3 & 3 & 3 & 3 & 3 \\
\hline ABCG & $23(42 \%)$ & $26(32 \%)$ & $23(23 \%)$ & 16 (31\%) & 13 (33\%) & $23(45 \%)$ & 15 (35\%) & 15 (27\%) & 13 (26\%) & $16(30 \%)$ & 13 (18\%) \\
\hline $\mathrm{ABCH}$ & $9(16 \%)$ & $11(13 \%)$ & $22(21 \%)$ & $3(6 \%)$ & $6(15 \%)$ & $2(3.9 \%)$ & $3(7 \%)$ & $3(5.3 \%)$ & $3(5.8 \%)$ & $3(5.5 \%)$ & $3(4 \%)$ \\
\hline Others & & 5 & & & 2 & & & & & & \\
\hline Total & 55 (100\%) & $82(100 \%)$ & 103 (100\%) & $52(100 \%)$ & 40 (100\%) & $51(100 \%)$ & $43(100 \%)$ & $56(100 \%)$ & $51(100 \%)$ & $54(100 \%)$ & 73 (100\%) \\
\hline
\end{tabular}

Species in this survey included Bemisia tabaci, Diuraphis noxia, Tetranychus urticae, Anopheles gambiae, Pediculus humanus humanus, Cimex lectularius, Bombyx mori, Helicoverpa armigera, Apis mellifera, Drosophila melanogaster, and Tribolium castaneum. "Others" refers to uncharacterized genes. The values without parentheses indicate the number of transporters detected; for subfamilies $A B C G$ and $A B C H$, the values in parentheses indicate the percentage of all $A B C$ transporters represented by the indicated subfamily

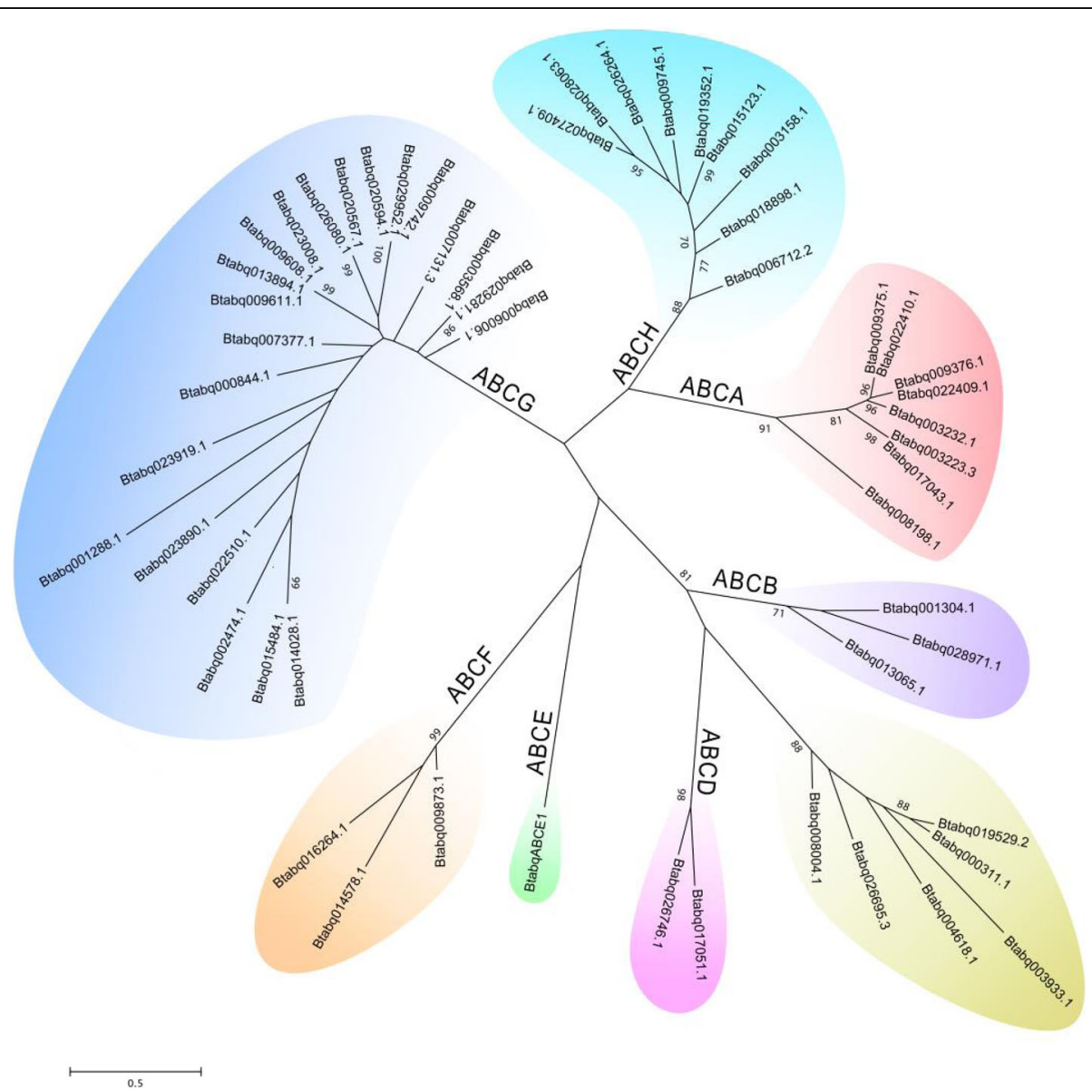

Fig. 1 Phylogenetic relationship of $55 \mathrm{ABC}$ transporters in B. tabaci Q. Amino acid sequences of nucleotide-binding domains (NBDs) were aligned using ClustalW and subjected to a maximum likelihood analysis by MEGA5 [97]. Numbers at the branch point of the node represent the value resulting from 1000 replications. All positions with less than 95\% site coverage were eliminated 
development [29]. Injection of dsRNAs synthesized from the two ABCA genes, TcABCA-9A and TcABC A-9B, led to approximately $30 \%$ mortality in the red flour beetle, $T$. castaneum [17].

\section{$A B C B$ subfamily}

In $B$. tabaci $\mathrm{Q}$, we identified three $\mathrm{ABCB}$ half-transporters but no full-transporters (Table 1). These B. tabaci halftransporters (Btabq001304.1, Btabq013065.1 and Btabq 013065.1) belong to three clades, indicating that these genes are homologous to ABCB genes in human, fruit fly and other insects (Additional file 3: Figure S3). Btabq001304.1 clustered with ABCB6 proteins from other species, including $D$. noxia DnXP_015376167.1, An. gambiae AGAP002278, D. melanogaster DmCG4225, T. japonicas TjABCB6, and $H$. sapiens $h A B C B 6$. Similarly, Btabq028971.1 formed an ABCB7 clade with $D$. noxia DnXP_015378905.1, D. melanogaster DmCG7955, T. japonicas TjABCB7, and $H$. sapiens $h A B C B 7$. Meanwhile, Btabq013065.1 was clustered with ABCB8 from $D$. melanogaster (DmCG1824), T. urticae (Tu17g02000), T. japonicas (TjABCB8) and H. sapiens (hABCB8).

In $H$. sapiens, hABCB6, hABCB7 and hABCB8/ $\mathrm{MABC} 1$ are mitochondrial transporters with roles in iron metabolism and transportation of $\mathrm{Fe} / \mathrm{S}$ protein precursors [30, 31]. Drosophila melanogaster DmCG4225 (ABCB6) was tolerant to cadmium [32]. Disruption of $C$. elegans ABTM- 1, a homologue of ABCB7, induced oxidative stress and premature cell death [33]. Furthermore, a homologous gene of $H$. sapiens ABCB7 in Aedes aegypti was up-regulated in an insecticide resistant strain [34]. Disruption of mouse ABCB8 decreased mitochondrial iron export and led to cardiomyopathy [35]. Similar to D. pulex, B. tabaci Q do not have homologous genes of human $A B C B$ half-transporters that were associated with antigen processing (hABCB2, hABCB3, and hABCB9) [13].

\section{ABCC subfamily}

Insects typically have different number of $\mathrm{ABCC}$ transporters (Table 2). In B. tabaci Q, we identified six ABCC full-transporters, including Btabq019529.2, Btabq000311.1, Btabq008004.1, Btabq026695.3, Btabq004618.1 and Btabq 003933.1. ABCC subfamily proteins are full-transporters with diverse functions, such as cell-surface receptor, ion transport and translocation of a broad range of substrates including drugs and endogenous compounds [36-39]. Due to their diverse functions, human ABCC subfamily members refer to multidrug resistance associated proteins (MRPs), which function as transporters; the cystic fibrosis transmembrane conductance regulator (CFTR, ABCC7), which forms a chloride channel; and sulfonylurea receptors (SUR1/2, ABCC8/9), which function as regulators of potassium channels [40]. In H. sapiens, "long" MRPs like
$\mathrm{ABCC} 1,2$, 3, 6 and 10 (MRP1, 2, 3, 6 and 7, respectively) have a TMD0, the third N-terminal transmembranespanning domain, while "short" MRPs like ABCC4, 5, 11 and 12 (MRP4, 5, 8 and 9, respectively) lack TMD0 [40].

In our phylogenetic analysis, two B. tabaci ABCC1 genes, Btabq019529.2 and Btabq000311.1, clustered with D. noxia DnXP_015366208.1, DnXP_015366209.1, D. melanogaster DmCG6214, T. japonicus ABCC1 and a group of $H$. sapiens "long" MRPs (MRP1, 2, 3 and 6) (Additional file 4: Figure S4). MRP1/ABCC1 transports a structurally diverse range of endogenous substances (e.g. leukotrienes and estrogen conjugates), xenobiotics and their metabolites [41]. These MRPs have been extensively studied as transporters of natural product drugs such as anthracyclines and plant alkaloids [42]. As a homologous gene to $H$. sapiens MRP1, MRP2, MRP3 and MRP6, DmCG6214 functions as a high capacity ATP-dependent organic anion transporter and acts as a transporter of ecdysteroid and juvenile hormone conjugates [43]. The other two ABCC genes in B. tabaci, Btabq008004.1 and Btabq026695.3, gathered with a large clade of ABCC4 in D. noxia, An. gambiae and a cluster of Drosophila ABCC proteins, including DmCG10505, DmCG14709 and others. MRP4/ABCC4 can remove a wide range of endogenous and exogenous molecules from cells [44]. The ABCC transporter encoded by CG10505 in D. melanogaster was regulated by heavy metals and was involved in biochemical detoxification of zinc and copper [45]. Drosophila DmCG14709 gene, a homologue of $H$. sapiens MRP4/ABCC4, was tightly regulated by oxygen [46]. The human body louse ABCC4 gene, $P h A B C C 4$, was up-regulated after exposed to the pesticide ivermectin. Injection of female lice with PhABCC4 dsRNA significantly increased their sensitivity to ivermectin [47].

Btabq004618.1 clustered with D. noxia DnXP_01537 3973.1, T. japonicas TjABCC7, D. melanogaster DmCG 7806, H. sapien hABCC10/MRP7 and T. urticae Tu03g 07840. hABCC10/MRP7 was able to transport amphipathic anions and conferred resistance to some antitumor drugs [48]. In addition, Btabq003933.1 clustered with sulfonylurea receptors (SURs) in D. noxia, D. melanogaster, T. japonicas, T. urticae and $H$. sapiens. Unlike other ABCC subfamily genes, SURs help form ATPsensitive potassium $\left(\mathrm{K}_{\mathrm{AT}} \mathrm{P}_{\mathrm{P}}\right)$ channels [38, 49]. Although SUR was considered to be a direct target of chitin synthesis inhibitors [50], it did not express in D. melanogaster epidermis, where chitin disruption was observed [51]. Moreover, data obtained from $D$. melanogaster suggested that chitin synthesis was independent of SUR [52]. Similarly, RNAi knockdown of SUR homologue in T. castaneum did not result in a phenotype [17]. ABCC subfamily is not only involved in detoxification and multidrug resistance in 
Manduca sexta but also participate in host plant selection in T. urticae $[10,53]$.

\section{$A B C D$ subfamily}

Bemisia tabaci $\mathrm{Q}$ has two $\mathrm{ABCD}$ transporters, Btabq026746.1 and Btabq017051.1 (Table 1). The same amount of $\mathrm{ABCDs}$ have also been found in other insects [8], while more $\mathrm{ABCDs}$ were identified in D. pulex, $H$. sapiens and C. elegans. Members of $\mathrm{ABCD}$ subfamily are half-transporters and involve in the import of fatty acids and acyl-CoAs into this organelle [55]. ABCD transporters participated in peroxisome-related developmental progress in C. elegans [56]. Mutations in hABCD1/ALDP gene resulted in adrenoleukodystrophy, a genetic disorder that occurs primarily in males [57]. Our phylogenetic analysis suggested that three clades of ABCDs in metazoans, with the two B. tabaci ABCDs distributed in two clades (Additional file 5: Figure S5). Btabq026746.1 clustered with D. noxia, DnXP_015374078.1, An. gambiae AGAP 002071, D. melanogaster DmCG216, T. japonicas TjAB $C D 2, H$. sapiens $h A B C D 2$ and $h A B C D 1$. Meanwhile, Btabq017051.1 belongs to ABCD3 clade.

\section{$A B C E$ and $A B C F$ subfamilies}

$A B C E$ and $A B C F$ subfamilies contain atypical $A B C$ transporters characterized by a pair of linked NBDs with no TMDs [1]. Their structure implied their roles in biological processes other than transportation. ABCE1 is one of the most evolutionarily conserved proteins and expressed in all organisms except eubacteria. Because of its role in translation and ribosome biosynthesis, $\mathrm{ABCE} 1$ is essential for all life stages [58]. Homo sapiens ABCE1/ RNase L was initially identified as an inhibitor of RNase $\mathrm{L}$ [58]. Members of the ABCE subfamily in human and yeast also have a role in translation initiation [59]. However, the $A B C E$ and $A B C F$ transporters have not been well characterized in invertebrates. RNAi knockdown of an $\mathrm{ABCE}$ gene, TcABCE-3A, resulted in significant mortality in penultimate $T$. castaneum larvae [17]. ABCE subfamily has only one member in all metazoans studied to date $[9,60]$, and B. tabaci follows this rule (BtabqABCE1, Table 1 and Additional file 6: Figure S6).

For ABCF subfamily, three transporters, Btabq009873.1, Btabq014578.1, and Btabq016264.1, were annotated and showed well-supported sister clades (Additional file 7: Figure S7). Btabq009873.1, Btabq014578.1, and Btabq 016264.1 were placed within the ABCF1, ABCF2, and $\mathrm{ABCF} 3$ clades, respectively. In human and yeast, $\mathrm{ABCF}$ proteins participated in gene regulation systems and ribosome assembly [14]. Mutations in the yeast GCN20 gene, which was involved in the initiation and control of translation, reduced Eif $2 \alpha$ phosphorylation and translation in the ribosome [61].
Knockdown of TcABCF-2A led to $100 \%$ mortality in penultimate $T$. castaneum larvae [17].

\section{ABCG subfamily}

ABCGs have a typical reverse domain architecture, with a NBD localized at the N-terminus and a TMD at the Cterminus (NBD-TMD). The ABCG transporters in metazoans are half-transporters and can be a functional transporter only after dimerization. In plants and fungi, however, ABCGs are full-transporters, also called pleiotropic drug resistance proteins (PDRs) [16, 62]. Because of their duplicated domain structure, yeast PDRs were not included in the phylogenetic analyses in this study.

ABCG proteins represent the largest $A B C$ subfamily (23 members) in B. tabaci (Table 1) and also form the largest ABC subfamily in D. noxia [63], An. gambiae [7], bed bug (Cimex lectularius) [64], human body louse (Pediculus humanus humanus) [65], Drosophila [1] and A. mellifera [8] (Table 2). According to Sturm et al. [13], the expansion of ABCG transporters in D. pulex and $D$. melanogaster genomes was resulted from extensive lineage specific gene duplications.

Among the 23 ABCG members in B. tabaci Q, 17 are ABCG1 and ABCG4 transporters. These ABCG1 and ABCG4 proteins clustered with those in D. noxia, An. gambiae, T. urticae, and D. melanogaster (DmCG9664, DmCG32091, DmCG4822, DmCG31689, DmCG9663, DmCG17646, DmCG5853 and DmCG3164) (Additional file 8: Figure S8). The ABCG4 gene has the same intron/ exon structure as ABCG1, suggesting that they arose by a relatively recent gene duplication event [66]. Similar to ABCG1, ABCG4 can be inducible by oxysterols and retinoids [67]. In H. sapiens, hABCG1 and hABCG4 were involved in cellular cholesterol efflux [68]. In addition, the elevated expression of ABCG4 in An. stephensi suggested its involvement in the degradation of a pyrethroid insecticide $[18,69]$.

Btabq001288.1 and Btabq001290.1 clustered with DnXP_01579755.1, DnXP_015379710.1, DmCG11069, DmCG31121, Tu01g16280, TjABCG5, hABCG5 and hABCG8. hABCG5 and hABCG8 mediated the intestinal and biliary efflux of cholesterol and sterols [68]. A clear subclass was formed with Btabq023890.1, D. melanogaster DmCG3327, and T. urticae tetur17g02510. DmCG3327 (also named E23), a 20-hydroxyecdysone (20E)-induced $\mathrm{ABC}$ transporter, regulated metamorphosis, probably by removing 20E from cells [70]. Similarly, ABCG expression in silkworm midgut was also regulated by $20 \mathrm{E}$ [8]. RNAibased functional study confirmed a similar role in metamorphosis of TcABCG-8A, a homologue of E23 in T. castaneum [17].

Among invertebrates, the functions of ABCGs were first characterized in Drosophila as pigment precursor transporters (brown, scarlet and white genes) [71, 72]. In 
our phylogenetic analysis, four B. tabaci ABCG proteins, Btabq014028.1, Btabq015484.1, Btabq002474.1 and Btabq022510.1, showed homologous relationships with these pigment precursor transporters in D. noxia, An. gambiae and D. melanogaster. Besides transporting pigment precursors, these transporters also function in courtship behavior [73], transport of biogenic amines [74] and up-take of uric acid [75]. RNAi-mediated suppression and genetic linkage analysis confirmed that down-regulation of Pxwhite gene was tightly linked to Cry1Ac resistance in Plutella xylostella [76].

Based on a recent review, $80 \%$ of the peer-reviewed publications involving arthropod $\mathrm{ABC}$ transporters (50) linked $\mathrm{ABC}$ transporters with insecticides-resistance [77]. Members of ABCG subfamily were over-expressed in thiamethoxam-resistant $B$. tabaci, suggesting the involvement of these genes in insecticide resistance [78]. In addition, ABCG subfamily not only participated in multipesticide resistance in $T$. urticae but also reduced the chemical defense from host plants [10]. In B. mori, at least five ABCG genes acted as 20-hydroxyecdysone (20E)-response genes and participated in hormonal regulation [8]. These results suggested that members of the ABCG subfamily play significant roles in the development and the removal of amphiphilic xenobiotics. Although $A B C$ transporters in subfamilies $\mathrm{B}, \mathrm{C}$, and $\mathrm{G}$ are involved in the metabolic resistance to various xenobiotics, B. tabaci $\mathrm{Q}$, however, contains predominantly $\mathrm{G}$, but few $\mathrm{B}$ and $\mathrm{C}$ family members (Table 2). This bias reflects the importance of ABCG subfamily in B. tabaci to fend off xenobiotic offences derived from host plants as well as agroecosystems.

\section{$A B C H$ subfamily}

As inverse half-transporters, $\mathrm{ABCH}$ proteins share the same domain architecture as ABCG transporters. $\mathrm{ABCH}$ transporters were first discovered in D. melanogaster and have only annotated in arthropods and zebrafish $[6,8,10,11,13,17] . \mathrm{ABCH}$ proteins have not been identified in fungi, $C$. elegans, plants and mammals $[1,16,54,62]$. ABCH subfamily was documented in zebrafish but not in catfish, fugu or cod [79].

A total of nine $\mathrm{ABCH}$ transporters were identified in B. tabaci. Phylogenetic analysis showed that $\mathrm{ABCH}$ subfamily members were species-specific. Bemisia tabaci $\mathrm{ABCH}$ clustered with genes in D. noxia with a high bootstrap value (Additional file 9: Figure S9). An RNAi screen of $D$. melanogaster genes revealed that silencing of D. melanogaster CG9990 was lethal [80, 81]. In two insecticide-resistant $P$. xylostella strains, an $\mathrm{ABCH}$ (Px014955), was the most up-regulated $\mathrm{ABC}$ transporter [82]. Knockdown of $T c A B C H-9 C$, an $\mathrm{ABCH}$ in T. castaneum, resulted in $100 \%$ larval mortality and a significant reduction of fecundity and hatching rate. In addition, $T$. castaneum larvae injected with TcABCH-9C dsRNA showed a lack of lipids in their epicuticle, indicating that $T c A B C H-9 C$ may be required for the formation of a waterproof barrier in the epicuticle [17]. In the cotton bollworm Helicoverpa armigera and Manduca sexta, the expression of $\mathrm{ABCH}$ subfamily was highly induced after larvae fed with secondary metabolites $[19,53]$.

\section{Expression profiles across developmental stages}

Based on RNA-seq data, all $55 \mathrm{ABC}$ transporters were expressed with a RPKM (Reads Per Kilobases per Million reads) $>1$ in at least one of the $B$. tabaci life stages (Additional file 10: Table S1). Members from $\mathrm{ABCE}$ and $\mathrm{ABCF}$ subfamilies were ubiquitous and expressed highly throughout $B$. tabaci developmental stages (Fig. 2). In the polyphagous spider mite, T. urticae, an ABCE (tetur30g01400), showed high expression level throughout the life cycle [10]. Moreover, TcABCE-3A transcripts were abundant in all developmental stages of T. castaneum [17]. The expression profile of ABCE genes in the intertidal copepod, T. japonicas, and sea lamprey, Petromyzon marinus, showed similar trends as well $[83,84]$. Btabq014578.1 (ABCF2) had the highest expression level throughout the life cycle. ABCE1, $A B C F 1$ and $A B C F 2$ were highly expressed in all developmental stages of B. tabaci. ABCF3, also ubiquitously expressed, exhibited a lower expression level. These gene expression patterns were consistent with the fundamental functions in ribosome biogenesis and translation regulation $[17,85,86]$. The results suggest that $\mathrm{ABCE}$ and $\mathrm{ABCF}$ transporters were possibly essential to maintain "housekeeping" function in B. tabaci.

The expression levels for ABCA transporters in $B$. tabaci were relatively low with the exception of Btabq003232.1 (ABCA3), which was highly expressed in all life stages (Fig. 2). ABCA3 is critical for the proper formation of lamellar bodies and surfactant function and may participate in surfactant phospholipid metabolism [87]. Btabq001304.1 (ABCB6) expressed in all life stages of $B$. tabaci and highly expressed in eggs and nymphs. Btabq028971.1 (ABCB7) expressed in all developmental stages, especially in the fourth nymph stage and adult. Btabq013065.1 (ABCB8) expressed in all stages but at a lower level than other $\mathrm{ABCB}$ genes. Homo sapiens $\mathrm{ABCB}$ half-transporters, $\mathrm{ABCB} 6, \mathrm{ABCB} 7, \mathrm{ABCB} 8$ and $\mathrm{ABCB} 10$, were localized at mitochondria and functioned in iron metabolism [88].

Expression levels of all ABCC members were documented in each developmental stage of B. tabaci $\mathrm{Q}$, and the expression patterns were different among these genes (Fig. 2). Only Btabq008004.1 was highly expressed throughout life stages (Fig. 2). The two B. tabaci ABCDs, Btabq026746.1 and Btabq017051.1, showed stable expressional level among different developmental stages (Fig. 2). Btabq026746.1 was highly expressed while 


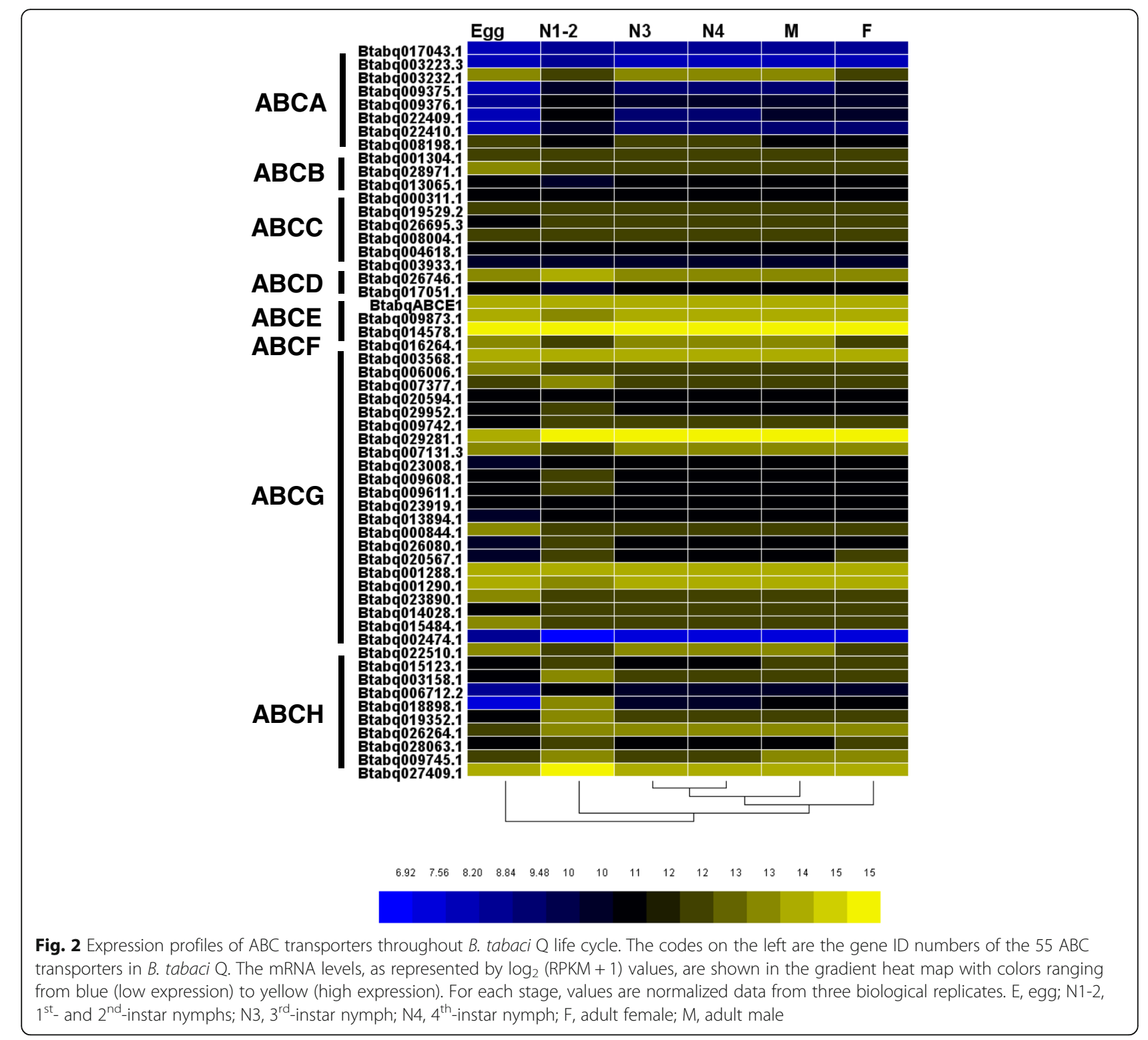

Btabq017051.1 showed slight lower expression level. Because the two ABCDs are homologous to those of mammal and insect transporters, similar functions such as roles in fatty acid metabolism can be inferred in $B$. tabaci Q.

Members of the ABCG subfamily showed different expression patterns in B. tabaci Q. Btabq003568.1, Btabq029281.1 and Btabq007131.3 were ubiquitously with high expression profiles. Expression levels were also high for Btabq006006.1, Btabq007377.1, Btabq029952.1 and Btabq000844.1. Overall, ABCG1 and ABCG4 members in B. tabaci $\mathrm{Q}$ had moderate to high expressional levels in all developmental stages. The ABCG4 in An. stephensi showed an increased expressional level in defense against the pyrethroid insecticide [18, 69]. Btabq001288.1 (ABCG5) and Btabq001290.1 (ABCG8) showed high expression in all stages of B. tabaci. Homologues of ABCG5 and ABCG8 in D. melanogaster and T. castaneum function, respectively, in metamorphosis [17] and may have a similar function in B. tabaci. Furthermore, Btabq022510.1 was annotated as a white gene and its expression level in nymph and adult stages was especially high. Recently, a Pxwhite gene was shown to be tightly linked to Cry1Ac resistance in P. xylostella [76].

$\mathrm{ABCH}$ transporters differed in expression patterns during B. tabaci development. Btabq027409.1 and Btabq 026264.1 were highly expressed in all developmental stages. Moreover, Btabq015123.1, Btabq009745.1, and Btabq019352.1 also showed high expression level, especially in the $4^{\text {th }}$-instar nymphs and adults. One $\mathrm{ABCH}$ subfamily gene, CG9990, was presumed to be involved in mortality [81]. Silencing of $T$. castaneum TcABCH-9C 
reduced oviposition and pupal molting [17]. $\mathrm{ABCH}$ transporters are highest expressed in the head of $\mathrm{H}$. armigera when the larvae were ingested secondary metabolism [19].

Expansion of ABCG and $\mathrm{ABCH}$ subfamilies do exist in B. tabaci Q. Combined with their expressional profiles, we suspect that these $\mathrm{ABCG}$ and $\mathrm{ABCH}$ genes are involved in development-related metabolism and in the detoxification of xenobiotics including insecticides and secondary metabolites from host plant.

mRNA expression of selected ABC transporters by RT-qPCR The expression profiles of 24 selected $A B C$ transporters were confirmed by the RT-qPCR (Fig. 3). Within ABCA subfamily, Btabq003232.1 had the highest expressional level, followed by Btabq008198.1 and Btabq017043.1. This trend is consistent with RNA-seq analysis. Similarly, gene expression level of $\mathrm{ABCB}$ genes from high to low was Btabq028971.2, Btabq001304.1 and Btabq013065.1. Expression profiles of $\mathrm{ABCC}, \mathrm{ABCD}, \mathrm{ABCE}$ and $\mathrm{ABCF}$ subfamilies were also consistent with our RNA-seq data. In ABCG subfamily, the trend persisted. Only two genes in $\mathrm{ABCH}$ subfamily, Btabq028063.1 and Btabaq026264.1, exhibited lower expressional level, which is not consistent with the RNA-seq data. Statistical analysis by SPSS demonstrated a significant correlation between transcriptome data and RT-qPCR data $(r=0.684, p<0.01)$.

\section{Transcriptional response to imidacloprid treatments}

A total of five genes were significantly up-regulated in imidacloprid-treated B. tabaci (Fig. 4, Additional file 11: Table S4). Btabq008198.1, an ABCA5 gene, can regulate accumulation of cholesterol [89]. The other four belong to ABCG subfamily, including Btabq003568.1 (ABCG1), Btabq020594.1 (ABCG1), Btabq007131.3 (ABCG4), and Btabq029281.1 (ABCG4).

The metabolic detoxification of xenobiotics likely involves a set of detoxification enzymes, which are general classified into three categories. Besides Phase I (e.g., cytochrome P450 monooxygenases) and Phase II (e.g., glutathione S-transferases), ABC transporters represent a major class of Phase III enzymes.

ABC transporters, especially those in the ABCG subfamily, facilitated $H$. armigera defense against secondary metabolites such as nicotine and tomatine [19]. The high expression of ABCG11 in $H$. armigera was the results of nicotine ingestion [19]. In addition, ABCG4 in An. stephensi was up-regulated in response to pyrethroid insecticide $[18,69]$. The expression levels of three ABC transporters, ABCG20-3, ABCG23-5 and $\mathrm{ABCH}-\mathrm{B}$, were higher in fieldcollected resistant populations of C. lectularius [90]. Then knockdown of ABCG20-3 reduced deltamethrin resistance [90]. ABC transporters, particularly ABCG1 and $\mathrm{ABCG} 4$, may have important role in response to xenobiotics. Moreover, ABCG4 gene has the same intron/exon structure as ABCG1, suggesting that they arose by a relatively recent gene duplication event [66]. Overall, feeding on imidacloprid significantly affected the expression of $\mathrm{ABC}$ transporters especially those in ABCG subfamily, suggesting the potential involvement of these genes in the $B$. tabaci metabolic resistance.

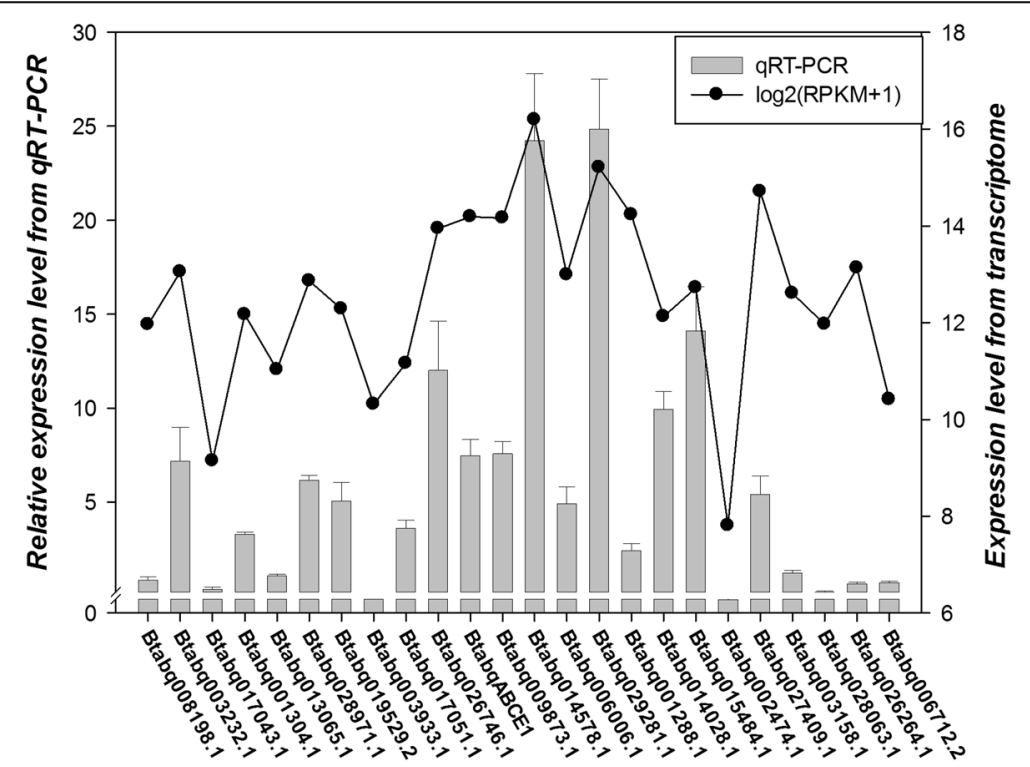

Fig. 3 mRNA expressions of selected B. tabaci Q ABC transporters by RT-qPCR. The bars represent expression level of $B$. tabaci Q ABC transporters relative to the Btabq008198.1. Data are presented as means \pm SE. Spots indicated $\log _{2}(R P K M+1)$ values of $A B C$ transporters in adults. Significant correlation between RT-qPCR and transcriptomic analyses were assessed by SPSS 


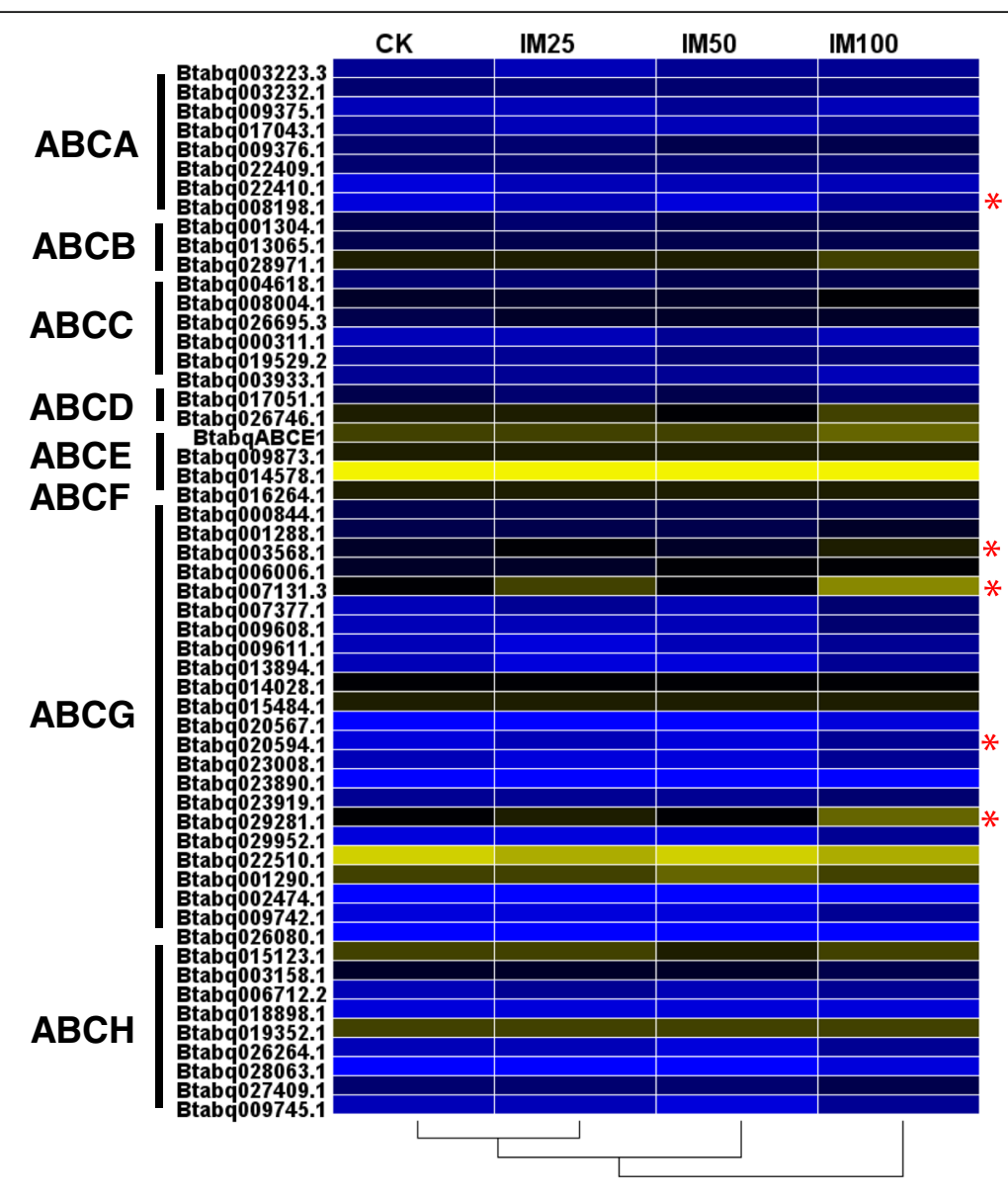

$\begin{array}{lllllllllllllll}0.38 & 0.92 & 1.45 & 1.99 & 2.52 & 3.06 & 3.59 & 4.13 & 4.66 & 5.20 & 5.74 & 6.27 & 6.81 & 7.34 & 7.88\end{array}$

Fig. 4 Transcriptional response of $A B C$ transporters in B. tabaci $Q$ adults to imidacloprid. The mRNA expression levels, i.e., log2 (RPKM + 1) values, are represented in a gradient heat map from low (blue) to high (yellow). Values were averaged from the three biological replications. The $B$. tabaci Q adults were fed with either water (CK) or imidacloprid at 25, 50, and $100 \mathrm{mg} / \mathrm{L}$ concentration (IM25, IM50, or IM100, respectively). An asterisk indicates a significant difference

\section{Conclusion}

In this study, we identified $55 \mathrm{ABC}$ transporters in the sweetpotato whitefly B. tabaci Q genome. ABC transporter subfamilies $\mathrm{G}$ and $\mathrm{H}$ are expanded in B. tabaci $\mathrm{Q}$ genome. The expression profiles of these $\mathrm{ABC}$ transporters were validated using both RT-qPCR and RNAseq analyses. Furthermore, $80 \%$ of the significantly upregulated $A B C$ transporters in imidacloprid-challenged B. tabaci were ABCGs. These combined results imply the potential contribution of ABCGs to the adaptability of this emerging global invasive pest.

\section{Methods}

\section{Colony maintenance and sample preparation}

Bemisia tabaci Q biotype (Mediterranean, MED) population maintained on cotton plant at $27 \pm 1{ }^{\circ} \mathrm{C}$, with a photoperiod of $16 \mathrm{~h}$ light: $8 \mathrm{~h}$ darkness and $70 \pm 10 \%$ relative humidity. Every 3-5 generations, the purity of the strain was monitored using a mitochondrial cytochrome oxidase I (mtCOI) marker [91].

The different developmental stage samples (eggs, four nymph stages, females and males) were collected from the $\mathrm{Q}$ biotype population described above. Newly emerged (within 5 days) adults of B. tabaci $\mathrm{Q}$ on cotton were collected to be treat with imidacloprid following adult leaf-dip bioassay method [92, 93]. In brief, leaf discs $(22 \mathrm{~mm}$ in diameter) from cotton plants were dipped in imidacloprid at 0 (distilled water control), 25, 50 and $100 \mathrm{mg} / \mathrm{L}$ for $10 \mathrm{~s}$. When dry, the leaf discs were placed on agar in a flat-bottomed glass tube, 20 B. tabaci adults were added to each tube. After $48 \mathrm{~h}$, adults were collected, snap frozen in liquid nitrogen, and transferred to $-80{ }^{\circ} \mathrm{C}$ for the long-term storage. Three biological replications for all B. tabaci samples were carried out 
independently. A total of 100 individuals were collected for each biological replication, and these samples were subjected to RNA-seq analysis.

\section{Identification and annotation of $A B C$ transporters}

To identify open reading frames (ORFs) encoding putative $\mathrm{ABC}$ transporters, we carried out tblastn searches against the B. tabaci $\mathrm{Q}$ genome [94] and transcriptome assembled from SRP064690. We subsequently used the highly conserved NBDs (as defined by InterPro domain IPR003439/ PF00005) and full-sequences of all $56 \mathrm{ABC}$ genes in $D$. melanogaster as queries to search against the updated GLEAN gene in B. tabaci genome with an E-value threshold of $10^{-5}$ to identify $\mathrm{ABC}$ transporters. Each putative $\mathrm{ABC}$ transporter gene was confirmed by subjected it to BLASTX analysis with the non-redundant protein sequence (NR) at GenBank (http://www.ncbi.nlm.nih.gov/).

The exon/intron boundary and start/stop codons of each $\mathrm{ABC}$ gene were confirm from the genome and transcriptome. The conserved domains of these identified ABC proteins were predicted using SMART (simple modular architecture research tool, http://smart.emblheidelberg.de/) [95] and confirmed by using the NCBI conserved domain search service tool. Putative Nglycosylation sites were predicted using NetNGlyc 1.0 server and $\mathrm{O}$-glycosylation sites were predicted using NetOGlyc 4.0 server [96].

\section{Phylogenetic analyses}

To analyze the evolutionary placement of $A B C$ transporters in $B$. tabaci, we collected the readily available $\mathrm{ABC}$ transporters from the fruit fly, D. melanogaster, wheat aphid, D. noxia, mosquito, An. gambiae, spider mite, T. urticae, intertidal copepod, T. japonicus, human, $H$. sapiens, nematode, Caenorhabditis elegans, and yeast, Saccharomyces cerevisiae. NBDs of B. tabaci ABC transporters were used to resolve their phylogenetic relationships at the subfamily level. Within each $\mathrm{ABC}$ subfamily, we used the full-length protein sequences to construct their respective phylogeny trees $[9,10]$. Additional file 12: Table S5 lists models of the constructed phylogenetic trees. Sequences of entire transporters aligned using ClustalW and then subjected to phylogenetic analysis by MEGA5 with 1000 bootstrap replications [97]. The phylogenetic trees were constructed using the maximum-likelihood method.

\section{Expression profiling of $A B C$ transporters}

Expression profiling of $\mathrm{ABC}$ transporters was assessed using transcriptome data of different developmental stages and imidacloprid-treated whitefly as described earlier. $A B C$ genes were also verified by quantitative real-time reverse transcription polymerase chain reaction (RT-qPCR). Total RNA was extracted using Trizol reagent according to the manufacturer's instructions (Invitrogen, Carlsbad, CA, USA). RNA was quantified using a Nanodrop 2000 (Thermo Scientific, Wilmington, DE, USA) meanwhile purity was checked on $1 \%$ agarose gels. RNA-seq libraries were constructed as previously described [98] and sequenced on a HiSeq 2500 system according to the manufacturer's instructions with sequenced at $125 \mathrm{bp}$ (PE125, library size is $280-320 \mathrm{bp}$ ). RNA-seq libraries of imidacloprid-treated samples were constructed by the same method and sequenced on a HiSeq 4000 system according to the manufacturer's instructions with sequenced at $150 \mathrm{bp}$ (PE150, library size is $450-550 \mathrm{bp})$. The raw reads were filtered with Fastq clean software [99] to trim low quality $(\mathrm{Q}$ value $<20) \mathrm{nu}-$ cleotides on both ends, clipping the adapter and barcode sequences from the 3 ' end and discarding the ribosomal RNA (rRNA) sequence. The high-quality cleaned reads were then aligned to the pre-prepared RNA sequence dataset with the Bowtie program [100] allowing one mismatch. After alignments, raw counts for each B. tabaci transcript and each sample were derived and were normalized to Reads Per Kilobase of transcript per Million mapped reads (RPKM). Differentially expressed genes (fold changes $>2$ and adjusted $P$-value $<0.05$ ) were identified by the DESeq package [101-103].

Besides transcriptomic validation, mRNA expressions of $\mathrm{ABC}$ transporters in B. tabaci $\mathrm{Q}$ biotype were confirmed using RT-qPCR analysis as well. Based on the RPKM value generated from the RNAseq data, we selected 24 transcripts representing all eight subfamilies of the $B$. tabaci $\mathrm{Q}$ biotype $\mathrm{ABC}$ transporters for the RT-qPCR validation study (Additional file 13: Table S2 and Additional file 14: Table S3). RTqPCR was conducted using an ABI PRISM 7500 Realtime PCR System (Applied Biosystems, Foster, CA, USA), and non-treated B. tabaci adults were subjected to the analysis. All RT-qPCR analyses included three technical replicates for each of three biological replicates. Elongation factor 1 (EF1) and TAF10 RNA polymerase II (TAF) were selected as reference genes $[104,105]$. The RT-qPCR was carried out in a $25 \mu \mathrm{L}$ reaction volume containing $12.5 \mu \mathrm{L} \quad 2 \times$ SuperReal PreMix Plus, $0.5 \mu \mathrm{L} 50 \times$ ROX Reference Dye, $0.75 \mu \mathrm{L}$ forward primer $(10 \mu \mathrm{M}), 0.75 \mu \mathrm{L}$ reverse primer $(10 \mu \mathrm{M}), \quad 1.0 \mu \mathrm{L} \quad \mathrm{cDNA}(300 \mathrm{ng} / \mu \mathrm{L})$, and $9.5 \mu \mathrm{L}$ RNase-free ddH2O, following the instructions of the SuperReal PreMix Plus (SYBR Green) kit (Tiangen, Beijing, China). The thermal cycling conditions were polymerase activation at $95{ }^{\circ} \mathrm{C}$ for $15 \mathrm{~min}$, followed by 40 cycles of denaturation at $95{ }^{\circ} \mathrm{C}$ for $10 \mathrm{~s}$, annealing at $60{ }^{\circ} \mathrm{C}$ for $30 \mathrm{~s}$ and elongation at $72{ }^{\circ} \mathrm{C}$ for $32 \mathrm{~s}$. The amplification efficiency was estimated using the equation: $E=\left[10^{\wedge}(-1 /\right.$ slope $\left.)-1\right] \times 100 \%$, in which the slope was derived from plotting the cycle 
threshold (Ct) value versus six serially diluted template concentrations. The transcript levels of $\mathrm{ABC}$ genes were quantified according to the $2^{-\Delta \Delta \mathrm{Ct}}$ method [106]. SPSS 19.0 was used to analyze correlations between RT-qPCR data and RNA-seq data.

\section{Additional files}

Additional file 1: Figure S1. Comparison of gene numbers in each subfamily of $A B C$ transporters between Bemisia tabaci and other organisms. (PDF $23 \mathrm{~kb}$ )

Additional file 2: Figure S2. Phylogenetic relationship of Bemisia tabaci $A B C A$ subfamily with other organisms. Full-length $A B C$ transporters were aligned using ClustalW and subjected to a maximum likelihood analysis by MEGA5 [97]. Numbers at the branch point of the node represent the values resulting from 1000 replications. Species, abbreviations, and color codes are: Btabq, B. tabaci (red); Dn, D. noxia (blue); AGA, A. gambiae (green); Dm, D. melanogaster (purple); Tu, T. urticae (light blue); Tj, T. japonicus (black); h, H. sapiens (gray); Ce, C. elegans (brick-red); Sc, Saccharomyces cervisiae (orange). (PDF $28 \mathrm{~kb})$

Additional file 3: Figure S3. Phylogenetic relationship of Bemisia tabaci $A B C B$ subfamily with other organisms. See Figure $\mathbf{S} 2$ legend for details. (PDF $14 \mathrm{~kb}$ )

Additional file 4: Figure S4. Phylogenetic relationship of Bemisia tabaci ABCC subfamily with other organisms. See Figure S2 legend for details. (PDF $15 \mathrm{~kb}$ )

Additional file 5: Figure S5. Phylogenetic relationship of Bemisia tabac $A B C D$ subfamily with other organisms. See Figure S2 legend for details. (PDF $19 \mathrm{~kb}$ )

Additional file 6: Figure S6. Phylogenetic relationship of Bemisia tabaci ABCE subfamily with other organisms. See Figure $\mathbf{S} 2$ legend for details. (PDF $37 \mathrm{~kb}$ )

Additional file 7: Figure S7. Phylogenetic relationship of Bemisia tabaci ABCF subfamily with other organisms. See Figure S2 legend for details. (PDF $89 \mathrm{~kb}$ )

Additional file 8: Figure S8. Phylogenetic relationship of Bemisia tabaci ABCG subfamily with other organisms. See Figure $\mathbf{S 2}$ legend for details. (PDF $16 \mathrm{~kb}$ )

Additional file 9: Figure S9. Phylogenetic relationship of Bemisia tabaci $\mathrm{ABCH}$ subfamily with other organisms. See Figure $\mathrm{S} 2$ legend for details. (PDF $134 \mathrm{~kb}$ )

Additional file 10: Table S1. RPKM values of $B$. tabaci $Q$ ABC transporters at different developmental stages (DOCX $13 \mathrm{~kb}$ )

Additional file 11: Table S4. Fold-change of gene expression following B. tabaci Q exposure to imidacloprid (DOCX $8 \mathrm{~kb}$ )

Additional file 12: Table S5. Models used for phylogenetic analysis (DOCX $15 \mathrm{~kb}$ )

Additional file 13: Table S2. Selected B. tabaci Q ABC transporters for the RT-qPCR validation study (DOCX $143 \mathrm{~kb}$ )

Additional file 14: Table S3. Primers used for the RT-qPCR analysis (DOCX $89 \mathrm{~kb})$

\section{Abbreviations}

20E: 20-hydroxyecdysone; ABC: ATP-binding cassette; CFTR: The cystic fibrosis transmembrane conductance regulator; MRP: Multidrug resistance associated protein; NBD: Nucleotide binding domain; PDR: Pleiotropic drug resistance protein; RPKM: Reads Per Kilobases of per Million reads; RTqPCR: Quantitative real-time reverse transcription polymerase chain reaction; SUR: Sulfonylurea receptor; TMD: Transmembrane domain.

\section{Acknowledgments}

Authors thank anonymous reviewers for their comments on the manuscript.

\section{Funding}

This work was supported by the National Natural Science Foundation of China (31420103919 and 31672032), and China Agriculture Research System (CARS-26 10). These agencies had no role in study design, data collection/ analysis, manuscript preparation, or the decision to publish.

\section{Availability of data and materials}

Bemisia tabaci Q ABC transporter dataset will be available from the corresponding authors on reasonable requests. Transcriptome datasets of $B$ tabaci $\mathrm{Q}$ at different development stages and following the exposure to imidacloprid insecticide have been deposited, respectively, in the Sequence Read Archive (SRA) database under the accession number SRP064690 and SRP090405.

\section{Authors' contributions}

$L T, X Z$ and $Y Z$ designed this research. $L T$ carried out the experiments, LT, TS, $\mathrm{RH}$ analyzed data. $\mathrm{XZ}$ and $\mathrm{YZ}$ contributed the materials and reagents. $\mathrm{LT}, \mathrm{WX}$ QW, SW, XZ and YZ revised the manuscript. All authors read and approved the final manuscript.

\section{Competing interests}

The authors declare that they have no competing interests.

\section{Consent for publication}

Not applicable

Ethics approval and consent to participate

Not applicable

\section{Publisher's Note}

Springer Nature remains neutral with regard to jurisdictional claims in published maps and institutional affiliations.

\section{Author details}

${ }^{1}$ Department of Plant Protection, Institute of Vegetables and Flowers, Chinese Academy of Agricultural Sciences, Beijing 100081, China. ${ }^{2}$ College of Life Science, Northeast Agricultural University, Harbin 150030, China. ${ }^{3}$ Department of Entomology, University of Kentucky, Lexington, KY 40546-0091, USA.

Received: 30 October 2016 Accepted: 12 April 2017 Published online: 26 April 2017

\section{References}

1. Dean M, Rzhetsky A, Allikmets R. The human ATP-binding cassette (ABC) transporter superfamily. Genome Res. 2001;11:1156-66.

2. Dassa E, Bouige P. The ABC of ABCs: a phylogenetic and functional classification of $A B C$ systems in living organisms. Res Microbiol. 2001;152:211-29.

3. Holland IB, Cole SP, Kuchler K, Higgins CF. ABC proteins: from bacteria to man. Academic Press. 2003.

4. Walker JE, Saraste M, Runswick MJ, Gay NJ. Distantly related sequences in the alpha- and beta-subunits of ATP synthase, myosin, kinases and other ATP-requiring enzymes and a common nucleotide binding fold. EMBO J. 1982;1(8):945.

5. Davidson AL, Dassa E, Orelle C, Chen J. Structure, function, and evolution of bacterial ATP-binding cassette systems. Microbiol Mol Biol Rev. 2008;72:317-64.

6. Dean M, Annilo T. Evolution of the ATP-binding cassette (ABC) transporter superfamily in vertebrates. Annu Rev Genom Hum G. 2005:6:123-42.

7. Roth CW, Holm I, Graille M, Dehoux P, Rzhetsky A, Wincker P, Weissenbach J, Brey PT. Identification of the Anopheles gambiae ATP binding cassette transporter superfamily genes. Mol Cells. 2003;15(2):150-8.

8. Liu S, Zhou S, Tian L, Guo E, Luan Y, Zhang J, Li S. Genome-wide identification and characterization of ATP-binding cassette transporters in the silkworm, Bombyx mori. BMC Genomics. 2011;12:491.

9. Dermauw W, Van Leeuwen $T$. The ABC gene family in arthropods: comparative genomics and role in insecticide transport and resistance. Insect Biochem Mol Biol. 2014:45:89-110.

10. Dermauw W, Osborne EJ, Clark RM, Grbić M, Tirry L, Van Leeuwen T. A burst of $A B C$ genes in the genome of the polyphagous spider mite Tetranychus urticae. BMC Genomics. 2013;14:317. 
11. Annilo T, Chen ZQ, Shulenin S, Costantino J, Thomas L, Lou H, Stefanov S, Dean M. Evolution of the vertebrate $A B C$ gene family: analysis of gene birth and death. Genomics. 2006;88:1-11.

12. Moon S, Jung $\mathrm{KH}$. Genome-wide expression analysis of rice $A B C$ transporter family across spatio-temporal samples and in response to abiotic stresses. J Plant Physiol. 2014;171(14):1276-88.

13. Sturm $A$, Cunningham $P$, Dean $M$. The $A B C$ transporter gene family of Daphnia pulex. BMC Genomics. 2009;10:170.

14. Tyzack JK, Wang X, Belsham GJ, Proud CG. ABC50 interacts with eukaryotic initiation factor 2 and associates with the ribosome in an ATP-dependent manner. J Biol Chem. 2000;275:34131-9.

15. Zhao Z, Fang $L L$, Johnsen $R$, Baillie DL. ATP-binding cassette protein $E$ is involved in gene transcription and translation in Caenorhabditis elegans. Biochem Biophys Res Commun. 2004;323:104-11.

16. Verrier PJ, Bird D, Burla B, Dassa E, Forestier C, Geisler M, Klein M, Kolukisaoglu U, Lee Y, Martinoia E, Murphy A, Rea PA, Samuels L, Schulz B, Spalding EJ, Yazaki K, Theodoulou FL. Plant ABC proteins-a unified nomenclature and updated inventory. Trends Plant Sci. 2008;13:151-9.

17. Broehan $\mathrm{G}$, Kroeger T, Lorenzen M, Merzendorfer H. Functional analysis of the ATP-binding cassette (ABC) transporter gene family of Tribolium castaneum. BMC Genomics. 2013:14:6.

18. Epis S, Porretta D, Mastrantonio V, Urbanelli S, Sassera D, De Marco L, Mereghetti $\mathrm{V}$, Montagna M, Ricci I, Favia G, Bandi C. ABC transporters are involved in defense against permethrin insecticide in the malaria vector Anopheles stephensi. Parasites Vectors. 2014;7:349.

19. Bretschneider A, Heckel DG, Vogel H. Know your ABCs: Characterization and gene expression dynamic $s$ of $A B C$ transporters in the polyphagous herbivore Helicoverpa armigera. Insect Biochem Mol Biol. 2016;72:1-9.

20. Brown JK, Coats SA, Bedford ID, Markham PG, Bird J, Frohlich DR. Characterization and distribution of esterase electromorphs in the whitefly, Bemisia tabaci (Genn.) (Homoptera: Aleyrodidae). Biochem Genet. 1995:33(7-8):205-14.

21. De Barro PJ, Liu SS, Boykin LM, Dinsdale AB. Bemisia tabaci: a statement of species status. Annu Rev Entomol. 2011;56:1-19.

22. Cahill M, Gorman K, Day S, Denholm I. Baseline determination and detection of resistance to imidacloprid in Bemisia tabaci (Homoptera: Aleyrodidae). Bull Entomol Res. 1996;86:343-9.

23. Horowitz AR, Kontsedalov S, Ishaaya I. Dynamics of resistance to the neonicotinoids acetamiprid and thiamethoxam in Bemisia tabaci (Homoptera: Aleyrodidae). J Econ Entomol. 2004;97:2051-6.

24. Nauen $\mathrm{R}$, Denholm I. Resistance of insect pests to neonicotinoid insecticides: current status and future prospects. Arch Insect Biochem. 2005;58(4):200-15.

25. Pan $H$, Preisser EL, Chu D, Wang $S$, Wu Q, Carrière $Y$, Zhang $Y$. Insecticides promote viral outbreaks by altering herbivore competition. Ecol Appl. 2015;25(6):1585-95

26. Decottignies A, Goffeau A. Complete inventory of the yeast $A B C$ proteins. Nat Genet. 1997:15:137-45

27. Li G, Shi P, Wang Y. Evolutionary dynamics of the ABCA, chromosome 17q24 cluster genes in vertebrates. Genomics. 2007;89(89):385-91.

28. Dutta S. Genetic regulation of autophagic cell death in Drosophila melanogaster (doctoral dissertation). 2008.

29. Lee CY, Wendel DP, Reid P, Lam G, Thummel CS, Baehrecke EH. E93, Directs Steroid-Triggered Programmed Cell Death in Drosophila. Mol Cell. 2000;6(2):433-43.

30. Krishnamurthy PC, Du G, Fukuda Y, Sun D, Sampath J, Mercer KE, Wang J, Sosa-Pineda B, Murti KG, Schuetz JD. Identification of a mammalian mitochondrial porphyrin transporter. Nature. 2006:443(7111):586-9.

31. Pondarré C, Antiochos BB, Campagna DR, Clarke SL, Greer EL, Deck KM, McDonald A, Han AP, Medlock A, Kutok UL, Anderson SA, Eisenstein RS, Fleming MD. The mitochondrial ATP-binding cassette transporter Abcb7 is essential in mice and participates in cytosolic iron-sulfur cluster biogenesis. Hum Mol Genet. 2006:15:953-64.

32. Sooksa-Nguan T, Yakubov B, Kozlovskyy VI, Barkume CM, Howe KJ Thannhauser TW, Rutzke MA, Hart JJ, Kochian LV, Rea PA, Vatamaniuk OK. Drosophila ABC transporter, DmHMT-1, confers tolerance to cadmium: DMHMT-1 and its yeast homolog, SpHMT-1, are not essential for vacuolar phytochelatin sequestration. J Biol Chem. 2009;284:354-62.

33. Gonzalez-Cabo P, Bolinches-Amoros A, Cabello J, Ros S, Moreno S, Baylis HA, Palau F, Vazquez-Manrique RP. Disruption of the ATP-binding cassette B7(ABTM-1/ABCB7) induces oxidative stress and premature cell death in Caenorhabditis elegans. J Biol Chem. 2011;286:21304-14.
34. Bariami V, Jones CM, Poupardin R, Vontas J, Ranson H. Gene amplification, ABC transporters and cytochrome P450s: unraveling the molecular basis of pyrethroid resistance in the dengue vector, Aedes aegypti. PLoS Negl Trop Dis. 2012:6(6):e1692.

35. Ichikawa Y, Bayeva M, Ghanefar M, Potini V, Sun L, Mutharasan RK, Wu R, Khechaduri A, Jairaj Naik T, Ardehali H. Disruption of ATP-binding cassette B8 in mice leads to cardiomyopathy through a decrease in mitochondrial iron export. Proc Natl Acad Sci U S A. 2012;109:4152-7.

36. Fukuda Y, Schuetz JD. ABC transporters and their role in nucleoside and nucleotide drug resistance. Biochem Pharmacol. 2012;83:1073-83.

37. Akrouh A, Halcomb SE, Nichols CG, Sala-Rabanal M. Molecular biology of K-ATP channels and implications for health and disease. IUBMB Life. 2009;61:971-8.

38. Jordan IK, Kota KC, Cui G, Thompson CH, McCarty NA. Evolutionary and functional divergence between the cystic fibrosis transmembrane conductance regulator and related ATP-binding cassette transporters. Proc Natl Acad Sci U S A. 2008;105:18865-70.

39. Kruh GD, Belinsky MG. The MRP family of drug efflux pumps. Oncogene. 2003;22:7537-52.

40. Deeley RG, Westlake C, Cole SPC. Transmembrane transport of endo- and xenobiotics by mammalian ATP-binding cassette multidrug resistance proteins. Physiol Rev. 2006:86:849-99.

41. He SM, Li R, Kanwar JR, Zhou SF. Structural and functional properties of human multidrug resistance protein 1 (MRP1/ABCC1). Curr Med Chem. 2011;18(3):439-81.

42. Borst $P$, Evers $R$, Kool M, Wijnholds J. A family of drug transporters: the multidrug resistance-associated proteins. J Natll Cancer I. 2000;92(16):1295-302.

43. Tarnay JN, Szeri F, Ilias A, Annilo T, Sung C, Le Saux O, Robinow S. The dMRP/CG6214 gene of Drosophila is evolutionarily and functionally related to the human multidrug resistance-associated protein family. Insect Mo Biol. 2004;13(5):539-48.

44. Russel FGM, Koenderink JB, Masereeuw R. Multidrug resistance protein 4 (MRP4/ABCC4): a versatile efflux transporter for drugs and signalling molecules. Trends Pharmacol Sci. 2008;29(4):200-7.

45. Yepiskoposyan H, Egli D, Fergestad T, Selvaraj A, Treiber C, Multhaup G, Georgiev O, Schaffner W. Transcriptome response to heavy metal stress in Drosophila reveals a new zinc transporter that confers resistance to zinc. Nucleic Acids Res. 2006;34:4866-77.

46. Huang H, Haddad GG. Drosophila dMRP4 regulates responsiveness to $\mathrm{O} 2$ deprivation and development under hypoxia. Physiol Genomics. 2007:29(29):260-6.

47. Yoon KS, Strycharz JP, Baek JH, Sun W, Kim JH, Kang JS, Pittendrigh BR, Lee SH, Clark JM. Brief exposures of human body lice to sublethal amounts of ivermectin over-transcribes detoxification genes involved in tolerance. Insect Mol Biol. 2011;20:687-99.

48. Hopper-Borge E, Xu X, Shen T, Shi Z, Chen ZS, Kruh GD. Human multidrug resistance protein 7 (ABCC10) is a resistance factor for nucleoside analogues and epothilone B. Cancer Res. 2009:69(1):178-84.

49. Bryan J, Muñoz A, Zhang X, Düfer M, Drews G, Krippeit-Drews P, Aguilar-Bryan L. $A B C C 8$ and $A B C C 9: A B C$ transporters that regulate $K^{+}$channels. Pflügers Archiv - Eur J Physiol. 2007;453(5):703-18.

50. Abo-Elghar GE, Fujiyoshi P, Matsumura F. Significance of the sulfonylurea receptor (SUR) as the target of diflubenzuron in chitin synthesis inhibition in Drosophila melanogaster and Blattella germanica. Insect Biochem Mol Biol. 2004;34:743-52.

51. Gangishetti U, Breitenbach S, Zander M, Saheb SK, Mueller U, Schwarz H, Moussian B. Effects of benzoylphenylurea on chitin synthesis and orientation in the cuticle of the Drosophila larva. Eur J Cell Biol. 2009;88:167-80.

52. Meyer F, Flötenmeyer M, Moussian B. The sulfonylurea receptor SUR is dispensable for chitin synthesis in Drosophila melanogaster embryos. Pest Manag Sci. 2013;69(10):1136-40.

53. Koenig C, Bretschneider A, Heckel DG, Grosse-Wilde E, Hansson BS, Vogel H. The plastic response of Manduca sexta to host and non-host plants. Insect Biochem Mol Biol. 2015;63:72-85.

54. Sheps JA, Ralph S, Zhao Z, Baille DL, Ling V. The ABC transporter gene family of Caenorhabditis elegans has implications for the evolutionary dynamics of multidrug resistance in eukaryotes. Genome Biol. 2004;5(3):1.

55. Theodoulou FL, Holdsworth M, Baker A. Peroxisomal ABC transporters. FEBS Lett. 2006:580:1139-55.

56. Petriv OI, Pilgrim DB, Rachubinski RA, Titorenko VI. RNA interference of peroxisome-related genes in C. elegans: a new model for human peroxisomal disorders. Physiol Genomics. 2002;10:79-91. 
57. Berger J, Gartner J. X-linked adrenoleukodystrophy: clinical, biochemical and pathogenetic aspects. Biochim Biophys Acta. 2006;1763(12):1721-32.

58. Barthelme D, Dinkelaker S, Albers SV, Londei P, Ermler U, Tampé R. Ribosome recycling depends on a mechanistic link between the FeS cluster domain and a conformational switch of the twin-ATPase ABCE1. Proc Natl Acad Sci U S A. 2011;108(8):3228-33.

59. Zhou A, Hassel BA, Silverman RH. Expression cloning of 2-5A-dependent RNAase: a uniquely regulated mediator of interferon action. Cell. 1993;72(5):753-65.

60. Chen ZQ, Dong J, Ishimura A, Daar I, Hinnebusch AG, Dean M. The essential vertebrate $A B C E 1$ protein interacts with eukaryotic initiation factors. J Biol Chem. 2006;281(11):7452-7.

61. Marton MJ, Vazquez de Aldana CR, Qu H, Chakraburtty K, Hinnebusch AG. Evidence that GCN1 and GCN20, translational regulators of GCN4, function on elongating ribosomes in activation of elF2 a kinase GCN2. Mol Cell Biol. 1997;17(8):4474-89.

62. Kovalchuk A, Driessen AJ. Phylogenetic analysis of fungal $A B C$ transporters. BMC Genomics. 2010;11(1):177.

63. Nicholson SJ, Nickerson ML, Dean M, Song Y, Hoyt PR, Rhee H, Kim C, Puterka GJ. The genome of Diuraphis noxia, a global aphid pest of small grains. BMC Genomics. 2015;16(1):1

64. Benoit JB, Adelman ZN, Reinhardt K, et al. Unique features of a global human ectoparasite identified through sequencing of the bed bug genome. Nat Commun. 2016;7.

65. Lee SH, Kang JS, Min JS, Yoon KS, Strycharz JP, Johnson R, Mittapalli O, Margam VM, Sun W, Li HM, Xie J, Wu J, Kirkness, Berenbaum MR, Pittendrigh BR, Clark JM. Decreased detoxification genes and genome size make the human body louse an efficient model to study xenobiotic metabolism. Insect Mol Biol. 2010;19(5):599-615.

66. Annilo T, Tammur J, Hutchinson A, Rzhetsky A, Dean M, Allikmets R. Human and mouse orthologs of a new ATP-binding cassette gene, ABCG4. Cytogenet Cell Genet. 2002;94(2-3):196-201.

67. Engel T, Lorkowski S, Lueken A, Rust S, Schluter B, Berger G, Cullen P, Assmann $G$. The human ABCG4 gene is regulated by oxysterols and retinoids in monocyte-derived macrophages. Biochem Biophys Res Commun. 2001;288(2):483-8.

68. Kusuhara $H$, Sugiyama Y. ATP-binding cassette, subfamily G (ABCG family). Pflugers Arch. 2007:453(5):735-44.

69. Epis S, Porretta D, Mastrantonio V, Urbanelli S, Sassera D, Marco L, Mereghetti V, Montagna M, Ricci I, Favia G, Bandi C. Temporal dynamics of the $A B C$ transporter response to insecticide treatment: insights from the malaria vector Anopheles stephensi. Sci Rep. 2014;4:7435.

70. Hock T, Cottrill T, Keegan J, Garza D. The E23 early gene of Drosophila encodes an ecdysone-inducible ATP-binding cassette transporter capable of repressing ecdysone-mediated gene activation. Proc Natl Acad Sci U S A. 2000;97(17):9519-24.

71. Sullivan DT, Grillo SL, Kitos RJ. Subcellular localization of the first three enzymes of the ommochrome synthetic pathway in Drosophila melanogaster. J Exp Zool. 1974;188(2):225-33.

72. Mackenzie SM, Brooker MR, Gill TR, Cox GB, Howells AJ, Ewart GD. Mutations in the white gene of Drosophila melanogaster affecting $A B C$ transporters that determine eye colouration. Biochim Biophys Acta. 1999;1419:173-85.

73. Zhang SD, Odenwald WF. Misexpression of the white (omega) gene triggers male-made courtship in Drosophila. Proc Natl Acad Sci U S A. 1995;92:5525-9.

74. Borycz J, Borycz JA, Kubow A, Lloyd V, Meinertzhagen IA. Drosophila ABC transporter mutants white, brown and scarlet have altered contents and distribution of biogenic amines in the brain. J Exp Biol. 2008;211:3454-66.

75. Tatematsu K, Yamamoto K, Uchino K, Narukawa J, lizuka T, Banno Y, Katsuma S, Shimada T, Tamura T, Sezutsu H, Daimon T. Positional cloning of silkworm white egg2 ( $w$-2) locus shows functional conservation and diversification of $\mathrm{ABC}$ transporters for pigmentation in insects. Genes Cells. 2011;16:331-42.

76. Guo Z, Shi K, Xun Z, Xia J, Wu Q, Wang S, Xie W, Zhang Y. Down-regulation of a novel $A B C$ transporter gene (Pxwhite) is associated with Cry $1 \mathrm{AC}$ resistance in the diamondback moth, Plutella xylostella (L.). Insect Biochem Mol Biol. 2015;59:30-40.

77. Porretta D, Epis S, Mastrantonio V, Ferrari M, Bellini R, Favia G, Urbanelli S. How heterogeneous is the involvement of $A B C$ transporters against insecticides? Acta Trop. 2016;157:131-5.

78. Yang NN, Xie W, Jones CM, Bass C, Jiao XG, Yang X, Liu BM, Li RM, Zhang YJ. Transcriptome profiling of the whitefly Bemisia tabaci, reveals stage- specific gene expression signatures for thiamethoxam resistance. Insect Mol Biol. 2013;22(5):485-96.

79. Liu S, Li Q, Liu Z. Genome-wide identification, characterization and phylogenetic analysis of 50 catfish ATP-binding cassette (ABC) transporter genes. PLoS One. 2013;8:e63895.

80. Mummery-Widmer JL, Yamazaki M, Stoeger T, Novatchkova M, Bhalerao S, Chen D, Dietzl G, Dickson BJ, Knoblich JA. Genome-wide analysis of Notch signalling in Drosophila by transgenic RNAi. Nature. 2009;458:987-92.

81. Zhang S, Feany MB, Saraswati S, Littleton JT, Perrimon N. Inactivation of Drosophila Huntingtin affects long-term adult functioning and the pathogenesis of a Huntington's disease model. Dis Model Mech. 2009;2:247-66.

82. You M, Yue Z, He W, Yang X, Yang G, Xie M, Zhan D, Baxter SW, Vasseur L, Gurr GM, et al. A heterozygous moth genome provides insights intoherbivory and detoxification. Nat Genet. 2013;45:220-5.

83. Jeong CB, Kim BM, Lee JS, Rhee JS. Genome-wide identification of whole ATP-binding cassette (ABC) transporters in the intertidal copepod Tigriopus japonicus. BMC Genomics. 2014;15(1):1-15.

84. Ren J, Chung-Davidson YW, Yeh CY, Scott C, Brown T, Li WM. Genome-wide analysis of the ATP-binding cassette (ABC) transporter gene family in sea lamprey and Japanese lamprey. BMC Genomics. 2015;16(1):1-14.

85. Pisarev AV, Skabkin MA, Pisareva VP, Skabkina OV, Rakotondrafara AM, Hentze MW. The Role of ABCE1 in Eukaryotic Posttermination Ribosomal Recycling. Mol Cell. 2010;37(2):196-210.

86. Paytubi S, Wang X, Lam YW, Izquierdo L, Hunter MJ, Jan E, Hundal HS, Proud CG. ABC50 promotes translation initiation in mammalian cells. J Biol Chem. 2009;284:24061-73.

87. Shulenin S, Nogee LM, Annilo T, Wert SE, Whitsett JA, Dean M. ABCA3 gene mutations in newborns with fatal surfactant deficiency. New Engl J Med. 2004;350(13):1296-303.

88. Zutz A, Gompf S, Schägger H, Tampé R. Mitochondrial ABC proteins in health and disease. BBA-Bioenergetics. 2009;1787(6):681-90.

89. DeStefano GM, Kurban M, Anyane-Yeboa K, Dall'Armi C, Di Paolo G, Feenstra H, Fantauzzo KA, et al. Mutations in the cholesterol transporter gene ABCA5 are associated with excessive hair overgrowth. PLoS Genet. 2014;10(5):e1004333.

90. Zhu F, Gujar H, Gordon JR, Haynes KF, Potter MF, Palli SR. Bed bugs evolved unique adaptive strategy to resist pyrethroid insecticides. Sci Rep. 2013;3:1456.

91. Zhang LP, Zhang YJ, Zhang WJ, Wu QJ, Xu BY, Chu D. Analysis of genetic diversity among different geographical populations and determination of biotypes of Bemisia tabaci in China. J Appl Entomol. 2005;129:121-8.

92. Feng $Y T$, Wu QJ, Xu BY, Wang SL, Chang XL, Xie W, Zhang YJ. Fitness costs and morphological change of laboratory-selected thiamethoxam resistance in the B-type Bemisia tabaci (Hemiptera: Aleyrodidae). J Appl Entomol. 2009;133:466-72.

93. Feng YT, Wu QJ, Wang SL, Chang XL, Xie W, Xu BY, Zhang YJ. Cross-resistance study and biochemical mechanisms of thiamethoxam resistance in B-biotype Bemisia tabaci (Hemiptera: Aleyrodidae). Pest Manag Sci. 2010;66:313-8.

94. Xie W, Chen C, Yang Z, Guo L, Yang X, Wang D, Chen M, Huang J, Wen Y, Zeng Y, Liu Y, Xia J, Tian L, Cui H, et al:: Genome sequencing of the sweetpotato whitefly Bemsia tabaci MED/Q. GigaScience. 2017;(in press).

95. Letunic L, Doerks T, Bork P. SMART: recent updates, new developments and status in 2015. Nucleic Acids Res. 2015;43(D1):D257-60.

96. Steentoft C, Vakhrushev SY, Joshi HJ, Kong Y, Vester-Christensen MB, Schjoldager KT, Lavrsen K, Dabelsteen S, Pedersen NB, Marcos-Silva L, Gupta R, Bennett EP, Mandel U, Brunak S, Wandall HH, Levery SB, Clausen $\mathrm{H}$. Precision mapping of the human O-GalNAC glycoproteome through Simple Cell technology. EMBO J. 2013;32(10):1478-88.

97. Tamura K, Peterson D, Peterson N, Stecher G, Nei M, Kumar S. MEGA5: molecular evolutionary genetics analysis using maximum likelihood, evolutionary distance, and maximum parsimony methods. Mol Boil Evol. 2011;28(10):2731-9.

98. Xie W, Guo L, Jiao X, Yang N, Yang X, Wu Q, Wang S, Zhou X, Zhang Y. Transcriptomic dissection of sexual differences in Bemisia tabaci, an invasive agricultural pest worldwide. Sci Rep. 2014;4:4088.

99. Zhang M, Sun H, Fei Z, Zhan F, Gong X, Gao S. Fastq clean: An optimized pipeline to clean the Illumina sequencing data with quality control. Bioinformatics and Biomedicine (BIBM), 2014 IEEE International Conference on. IEEE. 2014;44-48.

100. Langmead B, Trapnell C, Pop M, Salzberg SL. Ultrafast and memory efficient alignment of short DNA sequences to the human genome. Genome Biol. 2009;10(3):1. 
101. Xu Y, Gao S, Yang Y, Huang M, Cheng L, Wei Q, Fei Z, Gao J, Hong B. Transcriptome sequencing and whole genome expression profiling of chrysanthemum under dehydration stress. BMC Genomics. 2013;14(1):662.

102. Gao S, Ou J, Xiao K. R lanquage and Bioconductor in bioinformatics applications (Chinese Edition). Tianjin: Tianjin Science and Technology Translation and Publishing Co.; 2014.

103. Anders $\mathrm{S}$, Huber W. Differential expression analysis for sequence count data. Genome Biol. 2010;11:R106.

104. Li RM, Xie W, Wang S, Wu QJ, Yang NN, Yang X, Pan HP, Zhou XM, Bai LY, $X \mathrm{X} B \mathrm{BY}$, Zhou XG, Zhang YJ. Reference gene selection for qRT-PCR analysis in the sweetpotato whitefly, Bemisia tabaci, (Hemiptera: Aleyrodidae). Plos One. 2013;8(1):e53006.

105. Su YL, He WB, Wang J, Li JM, Liu SS, Wang XW. Selection of endogenous reference genes for gene expression analysis in the mediterranean species of the Bemisia tabaci (Hemiptera: Aleyrodidae) complex. J Econ Entomol. 2013;106(3):1446-55.

106. Schmittgen TD, Livak KJ. Analyzing real-time PCR data by the comparative CT method. Nat Protoc. 2008;3:1101-8.

Submit your next manuscript to BioMed Central and we will help you at every step:

- We accept pre-submission inquiries

- Our selector tool helps you to find the most relevant journal

- We provide round the clock customer support

- Convenient online submission

- Thorough peer review

- Inclusion in PubMed and all major indexing services

- Maximum visibility for your research

Submit your manuscript at www.biomedcentral.com/submit
Biomed Central 